\title{
Nurturing health-related online support groups: Exploring the experiences of patient moderators
}

\section{Neil S. Coulson \& Rachel L. Shaw}

\section{Introduction}

As access to the Internet has dramatically increased, particularly in the last decade (Internet World Stats, 2012), individuals living with a range of health-related problems have found new opportunities to come together for the purposes of information and advice sharing as well as mutual support (Powell et al., 2003 and Walther and Boyd, 2002). Furthermore, a number of unique characteristics of Internet-mediated communication have arguably underpinned a rise in the popularity of online support groups (White \& Dorman, 2001). For example, online support groups are not limited by geographical or temporal restrictions as might be the case for a face-to-face group (Braithwaite, Waldron, \& Finn, 1999). In addition, there is the potential for a much larger and diverse group composition (Wright \& Bell, 2003), which in turn allows members to potentially access a wider variety of information, advice and support (Coulson \& Knibb, 2007). Online support group members may also benefit from being able to disclose personal information (Suler, 2004) and discuss sensitive or embarrassing issues (Buchanan \& Coulson, 2007) with less fear of judgment or risk (Caplan, 2003 and Wright, 2000) as well as being able to develop more supportive relationships as a result of reduced visible social status cues, such as age, gender or ethnicity (King and Moreggi, 1998 and Madara, 1997).

To date, the vast majority of studies which have considered online support groups have sought to examine the online experiences of members either by analysing the nature of the communication which takes place (Blank, Schmidt, Vangsness, Monteiro, \& Santagata, 2010) or by asking them directly (e.g. Letorneau et al., 2012). This work has revealed a number of potentially important therapeutic processes which may benefit members and has been cited as evidence for the efficacy of health related online support groups (Coulson \& Malik, 2012). For example, members have been shown to be more informed, more in control, better able to accept and manage their illness, more confident in communicating with health professionals as well as experiencing improvements in self-esteem and general well-being (Bartlett and Coulson, 2011, Mo and Coulson, 2012, van Uden-Kraan et al., 2008 and Wright and Bell, 2003). However, online support groups are not without their limitations. For example, incorrect or misleading information, member conflict and disagreements, reading "horror" stories as well as the absence of physical connections with other members have all been described as having a negative impact on group members (Attard and Coulson, 2012, Esquivel et al., 2006, Han and Belcher, 2001, Hoybye et al., 2005 and Malik and Coulson, 2010).

To date, little attention has been given to understanding the factors which may contribute to the success (or not) of online support groups during the course of their existence. For example, the challenges of setting up and facilitating member interaction in a newly established group may differ from the challenges from groups which have been in existence for a longer period of time. One avenue through which we may explore the possible contributory factors underpinning the success (or not) of an online support group is through engaging with those individuals (usually patients) who moderate it. To date, there has been limited attention given to exploring the views of health-related online support group moderators and their role and function. One exception is that of van Uden-Kraan, Drossaert, Taal, Seydel, and van de Laar (2010) who interviewed 23 Dutch patients involved with three types of health-related online support group (i.e. breast cancer, fibromyalgia and arthritis), about their motives for setting up a support group and online experiences. The findings described how group moderators had a range of intrinsic as well as altruistic motives for starting an online group. In addition, a range of factors were identified in the process of setting up and initiation of an online support group. Whilst this study is important in helping explore the views of moderators, the range of groups included is limited to only three types of physical illness, restricted to the Dutch context and does not include representation from groups addressing mental health problems. As a consequence, 
these issues may limit the extent to which we can generalise across different types of support groups as well as understanding the processes important in helping shape the online support group once it has been initially set up.

\subsection{Aims}

The aim of this study was to examine the views of moderators across a diverse and geographically broad range of online support groups about their moderator experiences and to explore both the personal benefits as well as challenges involved.

\section{Methods}

\subsection{Procedure}

Participants to the study were recruited through individual invitations sent on behalf of the research team. Those moderators who wished to participate in the study were directed to an online questionnaire hosted by SurveyMonkey (an online survey and questionnaire tool), where they were provided with detailed information about the nature of the project and their rights as a research participant. In order to proceed, participants had to give their consent to be part of the study. In addition, they were asked to give permission to quote from their responses in the dissemination of the findings however, they could engage with the study regardless of whether they agreed to this or not. All participants subsequently agreed to this request. Next, each participant was asked to provide a six digit password in all correspondence with the research team or to withdraw their data from the study. Each participant was asked to disclose their age and gender. In addition, they were asked to indicate the online support group through which they had accessed the study and provide details of their role as a moderator including: number of members, length of time as group moderator, whether they are the moderator of any other online group as well as details about the registration procedure for each group and how a member can read and post to the group. Next, participants were asked to respond to a series of open-ended questions which were specifically concerned with their moderator role. For those participants who identified themselves as the original creator of the group $(\mathrm{N}=11)$, they were asked to further explain the reasons for creating the forum and the processes involved in doing so including any challenges. Following on from this, all participants were asked whether they moderated their online group alone or with others, the amount of time it takes up weekly, the personal benefits arising from their role as well as benefits for members, any negative aspects to the role and what they felt makes for a successful online support group, including advice for others thinking about starting one.

\subsection{Participant characteristics}

In total, 33 online support group moderators completed the questionnaire including 25 females and six males (two did not report their gender; participants are referred to as participant numbers, e.g. P1, P2, etc.). Participants ages ranged from 20 to 70 years (Mean $=48.48$ ). The size of the groups which participants moderated ranged from 4 to 33,000 with their length of service in this role ranging from 1 to 14 years (Mean $=6.27$ ). Nineteen participants reported that they had not previously or were not currently moderating another health-related online support group. Since some groups had multiple moderators which chose to participate in the study, the total number of unique health-related online support groups represented was twenty-four. A broad range of health and illnessrelated topics were represented including the following examples: diabetes, mouth cancer, thyroid disorders, neuromuscular disorders, Down's syndrome, breast cancer, obsessive compulsive disorder, sexual assault and arthritis.

\subsection{Data analysis}

The responses to the open-ended questions were analysed using inductive thematic analysis by the study authors, following the guidelines set out by Braun and Clarke (2006). The entire set of responses across all respondents was read several times by each coder in order to become familiar with the data and identify potential emerging themes. Following on from this, the coders discussed their analysis and together developed a thematic framework which was then used to code the responses independently. Following further discussion, the coders agreed a set of themes and data were identified to represent each of these. 


\section{Results}

Results are reported by theme with verbatim data extracts which describe the experience and life cycle of the online forum from the moderators' perspectives. Themes identified are emergence, empowerment, and nurturing.

\subsection{Emergence}

This theme reveals reasons cited for setting up the group. A simple reason for setting up a group was a felt need for it because no existing forum catered for people with a particular condition (additional data extracts are in Box 1):

Because at the time there just weren't any good support groups on line for those with Thyroid disorders. I had found help myself on line and chose to help others (P2).

Others initiated the forums to help educate people living with sometimes rare conditions, for example P6 described setting up an online forum to enable people to connect with each other between face-to face support meetings. A primary goal was to educate patients about treatments:

The online support community was founded originally to provide opportunities for members of an in person support group to be in contact between meetings. We received many queries from others who were not participants in our original group, and decided to open the forum to "anyone living with uveitis who wished to participate. Our primary mission was to educate patients about "modern" treatments for this rare disease, and to provide opportunities for mutual support (P6).

Others valued education and were either specialists themselves or had access to people who could provide expert advice:

Since we are providing support to a community of adults, parents, and children with a serious medical illness that affects vision, it has been invaluable to have a specialist physician advisor who can provide advice when asked (P12).

We know that increasing access to information can be beneficial in helping people manage their condition over time, particularly when rare or a number of treatment options are available.

In P6's account (see Box 1) we also see that ensuring people do not feel isolated is a key motivator for setting up the forum. Connecting with others experiencing the same condition and feeling validated by them is something moderators felt was important in the emerging identity of the online community:

Support first and foremost...and the knowledge that they are not the only ones out there with similar problems. A lot of people do not like face to face support (P24).

In fact, sharing experiences and caring for others represented strong drivers for the emergence of online forums and created a space where people living with the same condition could interact. Moderators' responses to a question about what members gain from participating also revealed that this feature was central to the ethos of the group:

I decided to set up an online support group so that survivors could support each other (P9).

This theme has shown largely altruistic reasons for setting up the online forums. Having been a patient in need of information and support themselves, many of these moderators set up forums to provide links and circulate valuable health information to individuals who otherwise may have been isolated and ignorant of treatment options. They also created a communal space for user interaction and peer support.

\subsection{Empowerment}

Here we describe the functions of the group from the moderators' perspectives but also gain insight into what moderators believe patients might gain from participation in the forum. Several moderators mentioned experiencing learning and growth through helping others: 
Being a moderator has helped me a great deal with my own healing. It has allowed me to turn a horrible experience into something positive (P18).

Acting as moderator constituted 'helper-therapy' for some which afforded them a sense of gratitude for being able to give something back and offer others the benefit of their experience:

This group helped me tremendously when I was diagnosed and I wanted to give something back. I am a web designer, so the moderation duties fit well with my skills (P7).

There is a clear link here to emergence above; the moderators' motivation for setting up or becoming involved in the management of forums fosters their own sense of empowerment. Having dealt with their own diagnosis as a patient and learned from it these moderators describe the value in being able to support others. Becoming an expert in their own condition and offering support to others is empowering because it provides an opportunity for moderators to share their received wisdom and prevent others from 'suffering in silence' the way they had to. This confers a feeling of competence to moderators which in turn is experienced as gratitude that they are able to give something back.

Moderators also reported that engaging regularly with the online group enabled them to learn more about their condition, to access a "communal brain" (P3; further data are presented in Box 2). This sense of the online forum as a resource hub is further illustrated by moderators' perception of it as an aid to help patients make treatment decisions along the care pathway. Some described the forum as boosting members' confidence to communicate effectively with health care professionals while others saw it as a gatekeeper to accessing services of which patients may not have been otherwise aware:

Welcome all newcomers and give advice openly - real advice rather than trying to couch answers in medical "speak" that confuses people new to the disease. [..] Give real advice and give out net addresses where they can also get more information. Don't be afraid to give out advice that could be useful while advising members to discuss everything with their doctors and also to do research on their own (P4).

P4's account shows that moderators need to be careful to convey a balanced approach between using their own experience to give advice and ensuring that members retain connections with the health services. The importance of accessing "traditional" sources of support provided by health care professionals also became apparent through P8's concerns that some members may depend too much on the online support group and instead of using it to help take responsibility for managing their condition depended on it in a passive way:

People don't understand what they read, they are intellectually lazy and want everything spoon fed to them. Far too many of the members complain about their chronic pain but when we show them that exercise, gaittraining and massage work better than analgesics, they become angry. There is a profound sense of helplessness that pervades the group. [..] It's almost as if most of the members resent the fact that they can help themselves. They appear to want external solutions (P8).

The experience of this moderator has led to disillusionment with the group's disengagement with health care services and self-management advice. Members are described as "lazy" and preferring a "quick fix" pill rather than making an effort to engage in constructive activities. There is a tension here between the forum being perceived as a supportive community which acts as a springboard for further learning and it becoming a crutch for people unable or unwilling to be proactive in self-managing their condition. While for most moderators the online forums offer a means of empowerment, there is a need to be cautious that they do not prevent patients from engaging with traditional, local health services.

\subsection{Nurturing}

In the final theme we discover what is required to nurture the forum and ensure it functions in an appropriate manner. Moderators were asked about their technical abilities to set up the forum initially. Several mentioned they benefited from free, open-access platforms, e.g. AOL, Yahoo, Google, and some forums were developed in 
association with existing websites. Some were novices ("internet stupid" P6) while others described themselves as "internet savvy" (P9). Once up and running our participants described soon learning that being a moderator took time (see Box 3). There was also a clear message that moderators need to set up boundaries in terms of determining what they are willing to give to the site in the context of (sometimes) their own daily experience as a patient:

There are times I feel this is not helping me move through stages I need to move through to live with this disease, yet not be so involved with it that it takes so much of my mental ability and time that I could be spending getting on with thing [sic] not involved with this bone disease. Personal growth for the owner/moderators need to be kept in mind (P1).

Arguably it is the moderator's own responsibility to set ground rules to protect their own well-being but P1's experience demonstrates how easy it can become overwhelming. Indeed, these moderators advise anyone thinking of taking on this role to think carefully before doing so and to actively engage in "self-care" (P22). This notion of "self-care" is particularly important for this group because so many of them are patients themselves. Furthermore, moderators told us that for those who have the condition themselves and who are therefore likely to have been through the same sorts of challenges that their members now face, it is imperative that they develop an emotional resilience:

Be prepared to take some heat on the tough calls. Members don't like being told they can't do something. Don't take insults personally (P18).

Part of the "armour" these moderators wear comes in the form of establishing clear rules of engagement and enforcing them. Dealing with "spam" (P10) and being able to spot "trolls" (P23) are early lessons. One participant said moderating was "like being a parent, you have to watch for someone breaking the rules" (26) and others gave the impression that dealing with "nasty emails" (P23) was commonplace.

A very clear message portrayed by these moderators was that they wanted to create a safe space for their members and that they were careful to nurture their group in order to protect this feeling of safety. To achieve this, moderators described a number of factors which must be in place, many of which come under the jurisdiction of the moderator to maintain:

Trust, confidentiality, fairness and courtesy. Many of newest members are scared and confused. They need to feel safe in asking questions without being judged or criticized (P7).

Moderators also described their nurturing role through their ability to "listen and give support and love" (P6) and offer "compassion, organisation and, patience" (P19). From these accounts it seems that creating a safe environment for members demands a balance between the characteristics listed above and clear guidance on appropriate conduct:

Participants must feel safe. To accomplish that, you must attempt to strike a balance between rule implementation while also allowing free expression. Moderators must always be empathic and compassionate. We must always remember that there are real people on the other side of the screen who deserve to be treated kindly (P23).

Kindness is a salient theme among these moderators' views about what is important in creating and managing a healthy online forum. This relates back to the first theme where we saw moderators setting up online groups through a desire to help others by sharing experiences and caring for them. The second theme showed us that moderators too gain from this experience and as many of them are patients themselves, it seems that whether a moderator or a member be, online forums for health conditions, when managed effectively, are a source for patient empowerment. 


\section{Discussion}

The aim of this study was to examine the views of moderators of a range of health-related online support groups about their moderator experiences and to explore both the personal benefits as well as challenges involved in undertaking their role.

Our findings describe a range of altruistic motives which appear to underpin the decision to become a moderator and to support the group and its members. It was common for group moderators to personally value the opportunity to both offer support to others as well as receive it. Furthermore, for some, their moderator role allowed them a means through which they could "give back" to the group. Within the literature, it has been widely acknowledged that the opportunity to offer as well as receive support is an important therapeutic process which is integral to support groups (Reisman, 1965). Indeed, this is known as the helper-therapy principle, where a member may feel an increased sense of self-efficacy and self-esteem through the process of helping others. In addition, this form of altruistic behaviour has also been shown to help individuals limit the extent to which they may be ruminating about their own problems (Shaw, Yeob Han, Hawkins, Mctavish, \& Gustafson, 2008). Our findings are consistent with a growing body of literature which supports the notion of the helper-therapy principle in the context of health-related online support groups (Shaw et al., 2008 and Winefield, 2006). In addition to the personal sense of gratification which moderators gain, offering support to others is also an important mechanism for helping sustain a healthy and productive online community. Lampel and Bhalla (2007) have argued that more 'experienced' or veteran members may feel especially motivated by the need to connect to and maintain the community, as opposed to new group members who may derive benefit by sharing their own experiences.

Our sample of moderators also described a range of ways through which group participants might benefit through interaction and mutual support online. In particular, the group was considered a "communal brain" and illustrates the potential for members to access a wealth of both factual and experiential information, advice and support. Indeed, there are several theoretical reasons as to why online support groups may help individuals cope better with illness. For example, Roter and Hall (1997) argue using their patient-communication theory that access to information may lead to changes in task behaviour. Thus, access to information from members of an online support group may influence a patient's behaviour in relation to how they attempt to manage their illness. Furthermore, according to Bandura (1977), access to information may also help participants' confidence in their ability to manage their condition.

According to moderators, through engaging with the group and connecting to similar others, members were being 'empowered' and benefiting in a number of important ways, such as increased confidence in accessing health services, interacting with health professionals and illness management. These findings are consistent with recent developments within the online support group literature which has considered the active online processes and subsequent outcomes from an empowerment perspective. Whilst the concept of empowerment is arguably complex and multidimensional, it broadly refers to the process through which individuals, organisations and communities gain control and mastery over issues that concern them. In the context of patient empowerment, it has been described as enhanced communication between the patient and health care professionals, a greater ability to selfmanage the condition as well as patients' autonomy and right to take responsibility for their own care and treatment-related decisions ( Anderson \& Funnel, 2010). Furthermore, emphasis is placed on patients' need to obtain information about their disease and available treatment options and other aspects of health care, which is necessary to enable their active participation in treatment decision-making. Increased knowledge and participation in making important decisions about their health-care can in turn enhance patients' sense of control over their illness and life in general ( Campbell et al., 2013, Mo and Coulson, 2012 and van Uden-Kraan et al., 2008).

However, our findings also suggest that this is a "double edged sword" in that the support offered through the group may, for some, lead to "laziness" and unwillingness to engage with traditional forms of healthcare. Thus, it seems that participation on online support groups may also have a disempowering impact on some members. However, thus far comparatively less empirical research has been undertaken which explores the negative consequences of 
online support group participation. Indeed, in patient surveys of negative consequences of participation (e.g. Malik \& Coulson, 2010), these problems have not been identified. However, this may be because members who respond to online surveys wish to present themselves in a positive light and therefore do not acknowledge that their online behaviour may not be helpful in managing their illness. This suggests that moderators may provide a unique insight into the impact of online support group participation and provide a means through which researchers can extend their understanding of this increasingly popular online phenomenon.

Finally, our findings also identify a number of challenges to the moderation role and how these can be managed. A notion of resilience was evident and suggests that over time moderators may equip themselves with the necessary skills required to effectively undertake the role. Our findings suggest that the experience of moderation, for those who have developed these personal skills and qualities, may be more manageable and less overwhelming.

Going forward, as the number of online support groups continues to increase as well as a growing number of patients choosing to access them for information, advice and support, more research is needed to understand the personal attributes, skills and resources required to effectively undertake the moderator role. In particular, researchers need to explore what factors underpin the development of personal resilience in moderators. The findings of such future research may be useful in terms of providing support and guidance for volunteer patients wishing to undertake a moderator function.

Whilst this study has identified a number of important factors in the development, facilitation and maintenance of health-related online support groups, there are a number of limitations which should be considered. First of all, this was a retrospective study which required participants to reflect on their moderation role. This approach may have introduced bias in terms of which experiences were salient at the time of participating in the study. Secondly, whilst our study did include a broader array of health-related topics, there is still a relative bias towards physical conditions and future work may seek to extend further the number and type of online support groups participating.

\subsection{Conclusions}

Online forums for health are increasingly popular. They provide information, support, and an interactive space for members to share experiences and advice. Many moderators are patients themselves who have become expert in a condition through living with it. This is beneficial to members because it provides access to information which can help boost their confidence in self-managing their condition; it is beneficial to moderators as 'helping-therapy' which develops their sense of mastery in managing their condition. In this way, moderating an online forum can enable the moderator and users to proactively manage their condition, to deal more effectively with health care professionals and to better access health care services available to them. Moderators themselves are encouraged to practise selfcare, but gratified by the sense of reciprocity in giving something back. 
- There was no support and no one to talk to about how I felt (P5).

- Because at the time there just weren't any good support groups on line for those with Thyroid disorders. I had found help myself on line and chose to help others (P2).

- I'm responsible for setting up my form [sic] on Shaz's Ostomy Pages. I set it up over 10 years ago because, at that time, there was only one other forum I could find, that supported ostomates and those going through surgery (P10).

- The online support community was founded originally to provide opportunities for members of an in person support group to be in contact between meetings. We received many queries from others who were not participants in our original group, and decided to open the forum to "anyone living with uveitis who wished to participate. Our primary mission was to educate patients about "modern" treatments for this rare disease, and to provide opportunities for mutual support (P6).

- In 1998, there was little on line layman info for the bone disease of osteonecrosis that generally hits younger folks 20-45 years old. It's not an easy to understand disease. I set it up to facilitate letting others know they are not alone, also to understand the disease physiologically since I am a clinical laboratory medical scientists [sic] and teach at the PhD level. Also, it was important to form a network of where to direct group members to MD's who are known to be better with this disease than others (P1).

- Since we are providing support to a community of adults, parents, and children with a serious medical illness that affects vision, it has been invaluable to have a specialist physician advisor who can provide advice when asked (P12).

- They get validation for there [sic] feelings, and hurts which can be quiet [sic] hard to come by in the general community - however online, without boarders [sic] and distance to limit the ability to communicate, it allows for members to much more effectively reach and community [sic] with others like themselves. It also allows for a high level of autoimmunity which offline group by there [sic] very nature are not able to offer (P17).

- Support first and foremost... and the knowledge that they're not the only ones out there with similar problems. A lot of people do not like face to face support (P24).

- $\quad$ There was no place currently for people with PA to share thoughts, feelings, experiences and information (P4).

- I I decided to set up an online support group so that survivors could support each other (P9).

- Support. Understanding. The ability to talk about things that they may not be able to talk about in a one-to-one situation. Information and suggestions regarding different ways of coping. Companionship (P21).

Box 2:Theme of empowerment

- $\quad$ Being a moderator has helped me a great deal with my own healing. It has allowed me to turn a horrible experience into something positive (P18).

- Encourages my own personal understanding of my own issues and helps me to understand the importance of reaching out to others. It has boosted my self esteem and the knowledge that I am helping to contribute to a good cause helps me to feel positive about myself. It has helped me to find my voice regarding my own issues (P21).

- $\quad$ Gratification in being able to help others with myasthenia gravis (P4).

- This group helped me tremendously when I was diagnosed and I wanted to give something back. I am a web designer, so the moderation duties fit well with my skills (P7).

- Personal benefits I have derived is seeing how much brighter group members are now the web has so much more information on it than back in the mid to end 90s. I also derive personal satisfaction anytime I hear, I am so glad to have found this group. I thought I would never meet anyone who understood what it is I face and am going through' (P1).

- In this we [sic] have multiple perspectives and points of view to many of the questions offered to the group (P3).

- I have learned a lot about my disease from other members (P27).

- $\quad$ Better understanding of the needs of patients and cares (P29).

- A place, too, where you learn something that would be of interest to the group, you can go share with them, contribute to the communal brain (P3).

- There are very few orthopedists [sic] who treat osteonecrosis. The average orthopod prefers to just replace the joints. Members of this group learn about the handful of surgeons who actively attempt to save joints and to treat the osteonecrosis. They also learn about the possible causes of osteonecrosis and of possible non-surgical treatments for idiopathic osteonecrosis (P8).

- Welcome all newcomers and give advice openly - real advice rather than trying to couch answers in medical "speak" that confuses people new to the disease. [..] Give real advice and give out net addresses where they can also get more information. Don't be afraid to give out advice that could be useful while advising members to discuss everything with their doctors and also to do research on their own (P4).

- People don't understand what they read, they are intellectually lazy and want everything spoon-fed to them. Far too many of the members complain about their chronic pain but when we show them that exercise, gait-training and massage work better than analgesics, they become angry. There is a profound sense of helplessness that pervades the group. [..] It's almost as if most of the members resent the fact that they can help themselves. They appear to want external solutions (P8). 
- Time is always an issue. I never feel I have enough time to donate and write enough. Group members want person replies. They don't want just directions of where to go to read something. They need to know a real person cares about them. So there is a lot of time spent with personal hand holding on repeat issues that continue to come as new group members come in (P1).

- There are times I feel this is not helping me move through stages I need to move through to live with this disease, yet not be so involved with it that it takes so much of my mental ability and time that I could be spending getting on with thing [sic] not involved with this bone disease. Personal growth for the owner/moderators need to be kept in mind (P1).

- Be sure you have the time to devote to the project and the compassion to do it with kindness. Know that you may be treated poorly by some members - but that more people will be grateful for your work than hurtful. Be aware of burnout - it is hard work emotionally. Practice self-care and take breaks when needed (P22).

- Know what you want to achieve, grow a thick skin, and keep a level head. Learn to walk away and not act rashly when topics flair up, and they will. New people always get moderated (P12).

- Be prepared to take some heat on the tough calls. Members don't like being told they can't do something. Don't take insults personally (P18).

- Trust, confidentiality, fairness and courtesy. Many of newest members are scared and confused. They need to feel safe in asking questions without being judged or criticized (P7).

- Diplomacy, respect and kindness. We are all equal no matter our status but as a role of moderator, it is up to me(us) to keep things under control (P28).

- Participants must feel safe. To accomplish that, you must attempt to strike a balance between rule implementation while also allowing free expression. Moderators must always be empathic and compassionate. We must always remember that there are real people on the other side of the screen who deserve to be treated kindly (P23).

\section{References}

R.M. Anderson, M.M. Funnel

Patient empowerment: Myths and misconceptions

Patient Education and Counseling, 79 (3) (2010), pp. 277-282

A. Attard, N.S. Coulson

A thematic analysis of patient communication in Parkinson's disease online support group forums

Computers in Human Behavior, 28 (2012), pp. 500-506

\section{A. Bandura}

Self-efficacy: Toward a unifying theory of behavioral change

Psychological Review, 84 (1977), pp. 191-215

K. Bartlett, N.S. Coulson

An investigation into the empowerment effects of using online support groups and how this affects doctor/patient communication Patient Education and Counselling, 83 (2011), pp. 113-119

T.O. Blank, S.D. Schmidt, S.A. Vangsness, A.K. Monteiro, P.V. Santagata

Differences among breast and prostate cancer online support groups

Computers in Human Behavior, 26 (2010), pp. 1400-1404

D.O. Braithwaite, V.R. Waldron, J. Finn

Communication of social support in computer mediated groups for people with disabilities

Health Communication, 11 (1999), pp. 123-151

V. Braun, V. Clarke

Using thematic analysis in psychology

Qualitative Research in Psychology, 3 (2006), pp. 77-101

H. Buchanan, N.S. Coulson

Accessing dental anxiety online support groups: An exploratory qualitative study of motives and experiences

Patient Education and Counseling, 66 (2007), pp. 263-269

K. Campbell, N.S. Coulson, H. Buchanan

Empowering processes within prostate cancer online support groups

International Journal of Web-Based Communities, 9 (2013), pp. 51-66

\section{S.E. Caplan}

Preference for online social interaction: A theory of problematic internet use and psychosocial well-being

Communication Research, 30 (2003), pp. 625-648 
N.S. Coulson, R.C. Knibb

Coping with food allergy: Exploring the role of the online support group

Cyber Psychology and Behavior, 10 (2007), pp. 145-148

N.S. Coulson, S. Malik

Health-related online support communities

Z. Yan (Ed.), Encyclopedia of cyber-behavior, IGI Global (2012)

A. Esquivel, F. Meric-Bernstam, E.V. Bernstam

Accuracy and self correction of information received from an Internet breast cancer list: Content analysis

British Medical Journal, 332 (2006), pp. 939-942

H.R. Han, A.E. Belcher

Computer-mediated support group use among parents of children with cancer: An exploratory study

Computers in Nursing, 19 (2001), pp. 27-33

M.T. Hoybye, C. Johansen, T. Tjornhoj-Thomsen

Online interaction effects of storytelling in an internet breast cancer support group

Psycho-oncology, 14 (2005), pp. 211-220

Internet World Stats. <http://www.internetworldstats.com/stats.htm>. August, 2012.

S.A. King, D. Moreggi

Internet therapy and self-help groups - The pros and cons

J. Gackenbach (Ed.), Psychology and the Internet: Intrapersonal, interpersonal, and transpersonal implications, Academic Press, San Diego, CA (1998), pp. 77-109

J. Lampel, A. Bhalla

The role of status seeking in online communities: Giving the gift of experience

Journal of Computer-Mediated Communication, 12 (2007), pp. 434-455

N. Letorneau, M. Stewart, J.R. Masuda, S. Anderson, L. Cicutto, S. McGhan et al.

Impact of online support for youth with asthma and allergies: Pilot study

Journal of Pediatric Nursing, 27 (2012), pp. 65-73

E.J. Madara

The mutual-aid self-help online revolution

Social Policy, 27 (1997), pp. 20-26

S. Malik, N.S. Coulson

"They all supported me but I felt like I suddenly didn't belong anymore": An exploration of the perceived disadvantages to online support seeking

Journal of Psychosomatic Obstetrics and Gynecology, 31 (2010), pp. 140-149

P.K.H. Mo, N.S. Coulson

Developing a model for online support group use, empowering processes and psychosocial outcomes for individuals living with HIV/AIDS

Psychology and Health, 27 (2012), pp. 445-449

J.A. Powell, M. Darvell, J.A.M. Gray

The doctor, the patient and the world-wide web: How the internet is changing healthcare

Journal of the Royal Society of Medicine, 96 (2003), pp. 74-76

F. Reisman

The "helper" therapy principle

Social Work, 10 (1965), pp. 27-32

D. Roter, J. Hall

Patient-provider communication theory

K. Glanz, F. Lewis, B. Rimer (Eds.), Health behavior and health education: Theory, research and practice (2nd ed.), Jossey Bass Publishers, San Francisco, CA (1997), pp. 206-226

B.R. Shaw, J. Yeob Han, R.P. Hawkins, F.M. Mctavish, D.H. Gustafson

Communicating about self and others within an online support group for women with breast cancer and subsequent outcomes Journal of Health Psychology, 13 (2008), pp. 930-939

J. Suler

The online disinhibition effect

Cyber Psychology and Behavior, 7 (2004), pp. 321-326 
C. van Uden-Kraan, C.H.C. Drossaert, E. Taal, E.R. Seydel, M.A.F.J. van de Laar

Patient-initiated online support groups: motives for initiation, extent of success and success factors

Journal of Telemedicine and Telecare, 16 (2010), pp. 30-34

C. van Uden-Kraan, C.H.C. Drossaert, E. Taal, B.R. Shaw, E.R. Seydel, M.A.F.J. van de Laar

Empowering processes and outcomes in online support groups for patients with breast cancer, arthritis or fibromyalgia

Qualitative Health Research, 18 (2008), pp. 405-417

J.B. Walther, S. Boyd

Attraction to computer-mediated social support

C.A. Lin, D. Atkin (Eds.), Communication technology and society: Audience adoption and uses, Hampton Press, Cresskill, NJ (2002), pp. 153-188

M. White, S.M. Dorman

Receiving social support online: Implications for health education

Health Education Research Theory and Practice, 16 (2001), pp. 693-707

H.R. Winefield

Support provision and emotional work in an Internet support group for cancer patients

Patient Education and Counselling, 62 (2006), pp. 193-197

K.B. Wright

Perceptions of on-line support providers: An examination of perceived homophily, source credibility, communication and social support within on-line support groups

Communication Quarterly, 48 (2000), pp. 44-59

K.B. Wright, S.B. Bell

Health-related support groups on the Internet: Linking empirical findings to social support computer-mediated communication theory Journal of Health Psychology, 8 (2003), pp. 39-54 